\title{
PILOT STUDY OF RECTUS SHEATH BLOCK IN CHILDREN
}

Lisa A. Isaac MD, Judith McEwen MB ChB, Jason Hayes MD, Mark W. Crawford MBBS

The Department of Anesthesia, The Hospital for Sick Children, University of Toronto, Toronto, M5G $1 \mathrm{X} 8$

INTRODUCTION Umbilical hernia repair, a common day surgery procedure in children, is associated with significant postoperative discomfort. The rectus sheath block may offer improved pain management following umbilical hernia repair. ${ }^{1,2}$ In this pilot study, we compared the analgesic efficacy of the rectus sheath block with that of infiltration of local anesthetic into the surgical wound (current local standard practice) for pain control after umbilical hernia repair in children.

METHODS With Research Ethics approval, 12 unpremedicated children 1 to 8 yrs of age undergoing umbilical hernia repair were studied. Children were randomly assigned to receive a rectus sheath block or local anesthetic infiltration into the surgical wound at completion of surgery. Anesthesia was induced with propofol $5 \mathrm{mg} / \mathrm{kg}$, fentanyl $1 \mu \mathrm{g} / \mathrm{kg}$, and rocuronium $0.6 \mathrm{mg} / \mathrm{kg}$. After tracheal intubation, anesthesia was maintained with isoflurane and $\mathrm{N}_{2} \mathrm{O}$. At completion of surgery, the assigned analgesic technique was performed using $0.8 \mathrm{ml} / \mathrm{kg}$ of $0.25 \%$ bupivacaine with epinephrine $1: 200,000$. Neuromuscular block was reversed and the trachea was extubated. Post-operatively, an observer blinded to the analgesic technique recorded CHEOPS pain scores and administered intravenous morphine $50 \mu \mathrm{g} / \mathrm{kg}$ every 10 minutes for CHEOPS scores $\geq 8$. Bromage sedation and CHEOPS scores were recorded every 10 min until CHEOPS score was $\leq 6$, and then every 15 min for one hour. Total morphine dose, complications, and time to discharge from PACU were recorded. Parents were telephoned the day following surgery to determine overall satisfaction with the pain control, both in hospital and at home. Data were compared using Mann-Whitney test.

RESULTS There were no significant differences in age and weight between the two groups. The dose of morphine administered did not differ significantly between groups. The box and whisker plot shows the median morphine dose, interquartile range, and range for each group. There were no significant differences in CHEOPS pain or Bromage sedation scores, and no complications. No parent expressed dissatisfaction with either technique.

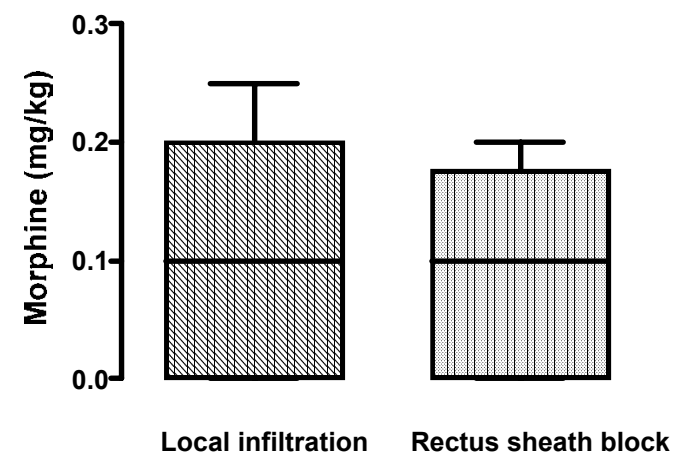

DISCUSSION These data suggest that the analgesic efficacy of the rectus sheath block is comparable to that of local infiltration into the surgical wound in children undergoing umbilical hernia repair.

REFERENCE: 1. Ped Anesth 6:463-6. 2. Ped Anesth 7:211-4 